\title{
DOCEAMUS
}

doceamus...let us teach

\section{Persistent Learning, Critical Teaching: Intelligence Beliefs and Active Learning in Mathematics Courses}

\author{
Benjamin Braun
}

Over the past several decades, social psychologists have built a substantial body of evidence showing that beliefs about the nature of intelligence have a major impact on motivation and achievement. Such beliefs generally fall into one of two types: The belief that each individual has a fixed ability in mathematics is referred to as a fixed intelligence belief. The belief that individuals are capable of continually developing their mathematical abilities through persistence and effort is referred to as a malleable intelligence belief. This article surveys recent research regarding the positive role malleable intelligence beliefs play for mathematics students and highlights connections between such beliefs and active learning techniques.

Benjamin Braun is assistant professor of mathematics at the University of Kentucky, Lexington. His email address is benjamin.braun@uky.edu.

The author dedicates this article to his parents, Jim and Pam Braun, for their unwavering belief in the potential of at-risk youth and children with disabilities.

Thanks to Jeff Blanchard, Laura Braun, David Bressoud, Steve Klee, Carl Lee, Katy Ott, and the anonymous reviewers for their thoughtful and extensive comments and suggestions.

Members of the Editorial Board for "Doceamus" are: David Bressoud, Roger Howe, Karen King, William McCallum, and Mark Saul.

DOI: http://dx.doi.org/10.1090/noti1066

\section{Beliefs about Intelligence}

Carol Dweck, currently a professor of psychology at Stanford, was one of the first researchers to emphasize the impact of intelligence beliefs on student learning. Much of Dweck's research has studied the fascinating effects of different types of praise on children [1, Chapter 3]. For example, her work shows that praise focused on developing malleable intelligence beliefs positively affects subsequent student achievement, while praise that cultivates fixed intelligence beliefs has the opposite effect. Dweck and her coauthors have recently turned their attention to the positive role malleable intelligence beliefs play in mathematics education, particularly for girls and women. Their research is interesting, because fixed intelligence beliefs are commonly expressed in mathematics; most of us regularly hear student comments such as "I'm bad at math" or hear teachers say their students are "hopeless at math."

In a thought-provoking survey article [4], Dweck describes how the math performance gap between male and female eighth-grade students is almost eliminated when one restricts comparison to those students holding malleable intelligence beliefs. She describes a similar phenomenon occurring with undergraduates in a pre-med chemistry course. In a study of undergraduate students in calculus courses [5], Good, Rattan, and Dweck find that 
female students who perceive malleable intelligence beliefs in their environment have a stronger sense of belonging in mathematics than female students who perceive an environment dominated by fixed intelligence beliefs. Further, students who themselves hold malleable intelligence beliefs are more likely to perceive the same in their learning environments. This study strongly suggests that the resulting sense of belonging has a positive impact on students' desire to pursue mathematics further.

In another recent work, Rattan, Good, and Dweck [10] provide evidence that when college-level mathematics teachers hold a fixed intelligence belief regarding their students and when this belief is reflected in student interactions, there is a negative impact on student self-beliefs and motivation. This belief is often conveyed by teachers through the use of well-intentioned "comforting" language, e.g., telling students that some people are not as good at math as others or that it is okay to not do well in math or telling a student that they will not be called on in class because the teacher knows it is stressful for them. Previous evidence of the effect of teacher feedback on student beliefs is found in work by Meyer et al. [8]. They find that praise given to students on easy tasks as a form of encouragement is interpreted by students as an evaluation of low competence, while constructive criticism given to students on difficult tasks is interpreted as an evaluation of high competence. In other words, students are adept at detecting when they are being patronized or implicitly put down; when this happens, what is intended to be supportive or comforting becomes instead demoralizing and insulting. Meanwhile, teachers convey a sense of confidence in their students when they provide appropriate challenges followed by critical analysis of student work.

\section{Active Learning}

One way to create a classroom environment that cultivates malleable intelligence beliefs, supporting students through sequences of challenges and critical responses, is the use of active learning techniques. These include many well-known methods: e.g., cooperative learning, peer-based instruction, guided discovery, and inquiry-based learning. While active learning techniques are not all identically effective and while they require persistence by teachers to be successfully applied, a growing body of evidence suggests that such methods generally have a positive effect on student learning and attitudes in mathematics [7], engineering [9], and other STEM disciplines [11, Chapter 6]. Active learning has also been studied extensively at the K-12 level; hence these methods deserve attention from mathematicians teaching courses aimed at future K-12 teachers.

One of the reasons that active learning methods are beneficial is that they create classroom environments focused on the intellectual and emotional growth of students, as opposed to teachers' transmission of various truths to an audience. Bain [2, Chapter 3] observes that the cultivation of such a classroom environment is a characteristic of highly effective college teachers across disciplines. Consider for example the familiar situation where a student can provide a formally correct statement of a definition or theorem that has been presented to him, yet the same student does not have a rich context in which to understand this formal statement: e.g., examples, nonexamples, related problems, standard misconceptions, etc. In this case, despite the successful transmission of a formal mathematical statement by a teacher, genuine student intellectual growth does not occur.

A useful language with which to describe this situation is provided by Tall and Vinner [12], who introduce the notions of concept definition and concept image to distinguish between the formal definition of a mathematical concept and the total individual cognitive structure associated with the concept, respectively. The important point of their work is that people tend to do creative mathematical thinking using their concept images rather than formal concept definitions; this underlies the typical mathematician's habit of generating small examples to get a feel for a problem. Mason [3, Chapter 20] expands the idea of concept image into a threefold framework consisting of awareness, emotion, and behavior that teachers can use when preparing to teach a concept. This extended framework supports the idea that teachers should seek to develop students' mathematical understanding in a multifaceted manner extending beyond the presentation of formally correct mathematics.

These ideas apply to mathematical practices as well as mathematical concepts. For example, individual understanding of "proof" changes dramatically over time [6, Chapter 2], and our shared standard and style for proof are a learned social construct. Selden [6, Chapter 17] surveys a broad range of research on expectations for student performance regarding proofs in K-12, undergraduate, and graduate courses, along with associated challenges for students in transition between these environments. In Seldon's article one finds multiple examples of active learning methods, from universities in almost a dozen different countries, focused on the teaching of mathematical reasoning and proof.

Active learning methods encourage a broad and gradual mathematical development on the 
part of students, including both mathematical content and mathematical practice, while implicitly emphasizing the importance of persistence and effort. It is immediate that such methods go hand-in-hand with malleable intelligence beliefs. Where active learning techniques underscore the malleable nature of learning, malleable intelligence beliefs provide an educational worldview in which students expect setbacks and failures as an ordinary part of the process of understanding.

\section{Conclusion}

It is important to remember that there is no "silver bullet" in teaching and that successful use of unfamiliar teaching methods requires patience and occasional failure. Also, as in all human endeavors, the exceptions break the rule: a lecture can sometimes help a student past his confusion; fixed intelligence beliefs can be beneficial in certain circumstances; and, obviously, students with malleable intelligence beliefs are not guaranteed success in a given mathematics course, since success in a course depends on many factors.

Despite these exceptions, the evidence given here supports cultivating malleable intelligence beliefs in our students and using active learning methods in our classrooms. It suggests that these activities have the potential to engage our students more fully, motivating them to seek deep understanding. These activities can help teachers develop a more nuanced vision of their students' experiences than traditional teaching methods. At their best, these activities can serve as catalysts to develop teachers and learners who value small failures as a step toward big success, who recognize learning as a complex process without end, and who believe in the potential of every student.

\section{References}

[1] J. Aronson (ed.), Improving Academic Achievement: Impact of Psychological Factors on Education, Academic Press, 2002.

[2] K. BAIN, What the Best College Teachers Do, Harvard University Press, 2004.

[3] M. CARLSON and C. RASMuSSEN (eds.), Making the Connection: Research and Teaching in Undergraduate Mathematics Education, MAA Notes \#73, Mathematical Association of America, 2008.

[4] C. S. DwECK, Is math a gift? Beliefs that put females at risk. In S. J. Ceci and W. M. Williams (eds.), Why Aren't More Women in Science? Top Researchers Debate the Evidence, American Psychological Association, 2006.

[5] C. GOod, A. RATTAN, and C. S. DWECK, Why do women opt out? Sense of belonging and women's representation in mathematics, Journal of Personality and Social Psychology 102 (2012), 700-717.

[6] G. Hanna and M. DE Villiers (eds.), Proof and Proving in Mathematics Education, Springer, 2012.

[7] S. Laursen, M. Hassi, M. Kogan, A. Hunter, and T. WeSTON, Evaluation of the IBL Mathematics
Project: Student and Instructor Outcomes of InquiryBased Learning in College Mathematics, Assessment \& Evaluation Center for Inquiry-Based Learning in Mathematics (report to the Educational Advancement Foundation and the IBL Mathematics Centers), University of Colorado, Ethnography \& Evaluation Research, 2011. http: //www. colorado. edu/eer/research/steminquiry.html

[8] W. MEYeR, M. BACHMANN, U. BieRMANN, M. HEMPELMANN, F. PLOGER, and H. SPILLER, The informational value of evaluative behavior: Influences of praise and blame on perceptions of ability, Journal of Educational Psychology 71, no. 2 (1979), 259-268.

[9] M. PRINCE, Does active learning work? A review of the research, J. Engr. Education 93, no. 3, (2004), 223-231.

[10] A. RatTAn, C. Good, and C. S. DweCK, "It's ok, not everyone can be good at math": Instructors with an entity theory comfort (and demotivate) students, Journal of Experimental Social Psychology 48 (2012), 731-737.

[11] S. R. Singer, N. R. NiELSEN, and H. A. SCHWEINGRUbeR (eds.), Discipline-Based Education Research: Understanding and Improving Learning in Undergraduate Science and Engineering, National Research Council, The National Academies Press, 2012.

[12] D. TALL and S. VINNER, Concept image and concept definition in mathematics, with special reference to limits and continuity, Educational Studies in Mathematics 12 (1981), 151-169. 